\title{
Estradiol Affects Extracellular Leptin: Adiponectin Ratio in Human Breast Tissue in Vivo
}

\author{
Vivian Morad, Annelie Abrahamsson and Charlotta Dabrosin
}

Linköping University Post Print

Tweet

N.B.: When citing this work, cite the original article.

Original Publication:

Vivian Morad, Annelie Abrahamsson and Charlotta Dabrosin, Estradiol Affects Extracellular Leptin: Adiponectin Ratio in Human Breast Tissue in Vivo, 2014, Journal of Clinical Endocrinology and Metabolism, (99), 9, 3460-3467.

http://dx.doi.org/10.1210/jc.2014-1129

Copyright: Endocrine Society http://endo.endojournals.org/

Postprint available at: Linköping University Electronic Press http://urn.kb.se/resolve?urn=urn:nbn:se:liu:diva-111611 


\title{
Estradiol Affects Extracellular Leptin:Adiponectin Ratio in Human Breast Tissue in Vivo
}

\author{
Vivian Morad, Annelie Abrahamsson, and Charlotta Dabrosin \\ Department of Oncology and Department of Clinical and Experimental Medicine, Linköping University, \\ Linköping, Sweden
}

\begin{abstract}
Context: Exposure to sex steroids is associated with increased breast cancer risk, and adipokines, leptin and adiponectin have been implicated in cancer progression. However, it is not known whether sex steroids affect adipokine secretion in breast tissue.
\end{abstract}

Objective: To elucidate the role of estrogen and tamoxifen on adipokine release in normal human breast tissue and breast cancer.

Setting and Design: Microdialysis sampling was used to collect extracellular in vivo leptin and adiponectin from normal human breast tissue in premenopausal healthy volunteers during the menstrual cycle and in postmenopausal women before tamoxifen treatment and after 6 weeks of treatment. In women with breast cancer, microdialysis was performed intratumorally before surgery. In addition, whole normal breast tissue biopsies were cultured ex vivo, and murine breast cancer models were evaluated.

Results: In normal breast tissue, plasma estradiol negatively correlated with local extracellular adiponectin levels $(r=-0.34 ; P<.05)$ and positively correlated with leptin $(r=0.37 ; P<.05)$ and leptin:adiponectin ratio $(r=0.38 ; P<.05)$. In postmenopausal women, tamoxifen treatment increased adiponectin $(P<0.05)$ and decreased leptin $(P<.01)$ and the leptin:adiponectin ratio $(P<$ $.01)$. These in vivo results were confirmed in breast tissue biopsies cultured ex vivo. In patients with breast cancer, extracellular leptin was higher $(P<.01)$ and adiponectin lower $(P<.05)$ in tumors than in normal adjacent breast tissue. In a murine model of breast cancer, estrogen exposure increased leptin secretion $(P<.05)$.

Conclusions: Estrogen exposure may have a critical role in the regulation of adipokines in human breast tissue and may serve as therapeutic targets for treatment and prevention. (J Clin Endocrinol Metab 99: 3460-3467, 2014)

$\mathbf{S}$ ex steroids play critical roles in the development and function of the human breast; however, prolonged exposure increases the risk of breast cancer $(1,2)$. Sex steroids may increase breast cancer risk through receptormediated mechanisms such as epithelial cell proliferation and by mechanisms unrelated to receptors for example via genotoxic metabolites; however, the exact mechanisms involved in sex steroid-dependent breast carcinogenesis remain unclear $(3,4)$. Most breast cancers express the estrogen receptor (ER) and may benefit from endocrine

\section{ISSN Print 0021-972X ISSN Online 1945-7197}

Printed in U.S.A.

Copyright (C) 2014 by the Endocrine Society

Received January 15, 2014. Accepted April 25, 2014.

First Published Online May 5, 2014 therapies (5). However, this therapy reduces the risk of recurrence by only $30-50 \%$ (6). For these reasons, there is an urgent need to develop new therapeutic options, which requires a better understanding of sex steroid-regulated pathways in normal breast tissue, as well as breast cancers.

Adipocytes, which are the most abundant cell type surrounding the epithelial cells in normal breast tissue, play important roles in the breast microenvironment by secreting a variety of bioactive molecules including growth fac-

Abbreviations: AdipoR1, adiponectin receptor 1; AdipoR2, adiponectin receptor 2; BMI, body mass index; E2, 17 $\beta$-estradiol; ER, estrogen receptor; LepR, leptin receptor; MMTV, mouse mammary tumor virus; PR, progesterone receptor; PyMT, polyoma middle $T$. 
tors, angiogenic factors, and proinflammatory cytokines (7). One of these bioactive molecules is leptin, a $16-\mathrm{kDa}$ adipokine that acts on target cells by binding to the membrane-associated leptin receptor (LepR). In breast cancer, leptin seems to increase cell proliferation, up-regulate estrogen receptor- $\alpha(\mathrm{ER} \alpha)$, and increase expression of aromatase and vascular endothelial growth factor, thereby promoting angiogenesis $(8-10)$. However, clinical studies have not yet clarified the relationship between leptin level and breast cancer risk (11). Adiponectin, a $30-\mathrm{kDa}$ adipokine that also appears to be important in the development and progression of breast cancer (12), mediates its effects through binding adiponectin receptor 1 (AdipoR1) and adiponectin receptor 2 (AdipoR2) (13). Low serum levels of adiponectin have been associated with increased breast cancer risk $(12,14,15)$; thus leptin and adiponectin seem to have opposing effects in breast cancer $(16,17)$. Hence, the ratio of these two adipokines may be physiologically more relevant than the absolute concentrations of either protein $(18,19)$.

The inability to establish a relationship between circulating levels of adipokines and breast cancer risk may be explained, at least in part, by a lack of correlation between blood levels and local tissue levels. Leptin and adiponectin exert their effects in the extracellular space within tissues; therefore, these proteins should be collected from the extracellular space of target tissues to elucidate their roles. In the present study, we evaluated whether it was possible to collect extracellular leptin and adiponectin in vivo in normal human breast tissue and in breast cancer tumors. We hypothesized that estrogen exposure influences adipokine levels, and that tamoxifen treatment could normalize adipokine levels in situ.

We collected extracellular leptin and adiponectin from 1) normal breast tissue of healthy premenopausal women, 2) normal breast tissue of postmenopausal women (before and after tamoxifen therapy), 3) breast cancers of women before surgery, and 4) murine models of breast cancer. We showed that sex steroids and tamoxifen alter leptin and adiponectin levels in normal breast tissue, and that human breast cancer tissue express increased leptin levels and decreased adiponectin levels compared with the adjacent normal breast tissue. These in vivo results were supported by ex vivo breast tissue culture and experimental breast cancer in mice.

\section{Materials and Methods}

\section{Human subjects}

This study was approved by the regional ethical review board of Linköping, and all participants gave their informed consent. A total of 40 women underwent microdialysis sampling. In 29 of these women, microdialysis was performed in normal healthy breast tissue and sc abdominal fat (Table 1). Eleven of the 29 were premenopausal women (age 20-30 years; mean body mass index (BMI), $24.1 \pm 0.4$ ) with a history of regular menstrual cycles (27-35 days). In these women, microdialysis was performed twice during one menstrual cycle, in the follicular phase and in the luteal phase. Eighteen of the 29 were postmenopausal women (age 58-78 years; BMI, $26 \pm 0.92$ ) who had undergone surgical removal of early breast cancer. In these women, microdialysis was performed in the normal unaffected breast before the start of tamoxifen adjuvant therapy $(20 \mathrm{mg} / \mathrm{d})$ and again after 6 weeks of treatment; all women had a normal breast examination and mammography before the start of tamoxifen. All 29 women had been off sex steroid-containing medication such as contraceptive pills or hormone replacement therapy for more than 3 months.

The remaining 11 participants were postmenopausal women (age 52-83 years; BMI, $25 \pm 1.35$ ) with active breast cancer. Before surgical removal of the cancer tissue, microdialysis sampling was performed in the tumor and in the normal adjacent breast tissue. Tumor histology and size; immunohistochemistry analysis of the estrogen receptor (ER), progesterone receptor (PR), human epidermal growth factor receptor 2 (HER-2); and Nottingham histological grade (the Elston Ellis modification of the Scarff-Bloom-Richardson grading system) were determined

Table 1. Microdialysis Sampling of Adipokines in Normal Breast Tissue

\begin{tabular}{|c|c|c|}
\hline Participants & Microdialysis No. 1 & Microdialysis No. 2 \\
\hline \multirow{3}{*}{$\begin{array}{l}\text { Premenopausal women investigated } \\
\text { during a single menstrual cycle }\end{array}$} & Follicular phase & Luteal phase \\
\hline & $\begin{array}{l}\text { Catheter } 1 . \text { Implanted in normal } \\
\text { breast tissue }(n=11)\end{array}$ & $\begin{array}{l}\text { Catheter } 1 . \text { Implanted in normal } \\
\text { breast tissue }(n=11)\end{array}$ \\
\hline & $\begin{array}{l}\text { Catheter } 2 \text {. Implanted in sc abdominal } \\
\text { fat tissue }(n=11)\end{array}$ & $\begin{array}{l}\text { Catheter } 2 \text {. Implanted in sc abdominal } \\
\text { fat tissue }(n=11)\end{array}$ \\
\hline \multirow{2}{*}{$\begin{array}{l}\text { Postmenopausal women with previously } \\
\text { surgically removed early breast cancer }\end{array}$} & Before the start of tamoxifen & After 6 wk of tamoxifen $(20 \mathrm{mg} / \mathrm{d})$ \\
\hline & $\begin{array}{l}\text { Catheter } 1 \text {. Implanted in contralateral } \\
\text { normal healthy unaffected breast tissue } \\
(n=18) \\
\text { Catheter } 2 \text {. Implanted in sc abdominal } \\
\text { fat tissue }(n=16)\end{array}$ & $\begin{array}{l}\text { Catheter } 1 \text {. Implanted in contralateral } \\
\text { normal healthy unaffected breast } \\
\text { tissue }(n=18) \\
\text { Catheter } 2 \text {. Implanted in abdominal } \\
\text { fat abdominal tissue }(n=16)\end{array}$ \\
\hline
\end{tabular}


at the Department of Pathology and Cytology, University Hospital of Linköping (Table 2). In addition, biopsies from human breast tissue were obtained from premenopausal women undergoing routine reduction mammoplasty.

\section{Experimental procedures}

Before microdialysis catheter insertion, $0.5 \mathrm{ml}$ lidocaine $(10 \mathrm{mg} /$ $\mathrm{mL})$ was injected intracutaneously. In the healthy premenopausal women, one microdialysis catheter was placed in the upper lateral quadrant of the left breast, and another was placed in the sc abdominal fat as previously described (20-23). In the women receiving tamoxifen, one microdialysis catheter was placed in the upper lateral quadrant of the unaffected breast and another was placed in sc abdominal fat. In patients with breast cancer before surgery, one microdialysis catheter was placed intratumorally, and another was placed in adjacent normal breast tissue.

The microdialysis catheters (CMA 71/Microdialysis AB) consisted of tubular dialysis membranes $(100-\mathrm{kDa}$ cutoff; membrane length, $20 \mathrm{~mm}$ for normal breast tissue and $10 \mathrm{~mm}$ for breast cancer tumor). The catheters were connected to a pump (CMA 107, CMA/Microdialysis AB) and perfused with $\mathrm{NaCl}$ $(154 \mathrm{mM})$ and hydroxyethyl starch $(60 \mathrm{~g} / \mathrm{l}$ at $0.5 \mu \mathrm{l} / \mathrm{min})$ (Voluven, Fresenius Kabi, Uppsala, Sweden). After a 60-minute equilibration period, the samples were collected and stored at $-70^{\circ} \mathrm{C}$. All microdialysis values are given as original raw data.

\section{Breast tissue culture}

Breast tissue biopsies containing epithelium, stroma, and adipose tissue were obtained using an 8-mm biopsy punch (Kai Europe $\mathrm{GmbH}$ ) on resected tissue from reduction mammoplasties and placed in a 12-well plate (Costar) with serum-free medium consisting of a 1:1 mixture of nutrient mixture F-12 (GIBCO) and Dulbecco's modified Eagle's medium without phenol red (GIBCO) supplemented with transferrin $(10 \mu \mathrm{g} / \mathrm{mL}$; Sigma), insulin ( $1 \mu \mathrm{g} / \mathrm{mL}$; Sigma), and BSA (0.2 mg/mL; Sigma). The biopsies were cultured with or without physiological levels of $10^{-9} \mathrm{M}$ estradiol (17 $\beta$-estradiol (E2); Sigma), a combination of $10^{-9} \mathrm{M}$ estradiol and $10^{-8} \mathrm{M}$ progesterone (P4; Sigma) (E2 $+\mathrm{P} 4)$, or $10^{-6} \mathrm{M}$ tamoxifen (Sigma). The biopsies were incubated for 7 days at $37^{\circ} \mathrm{C}$ with $5 \% \mathrm{CO}_{2}$ with daily medium

Table 2. Characteristics of Patients who Underwent Intratumoral Microdialysis Sampling

\begin{tabular}{llllll}
\hline Patient & $\begin{array}{l}\text { Age, } \\
\mathbf{y}\end{array}$ & $\begin{array}{l}\text { Tumor } \\
\text { Size, mm }\end{array}$ & $\begin{array}{l}\text { Grade } \\
\text { (NHG) }\end{array}$ & ER, \% & PR, \% \\
\hline 1 & 68 & 24 & 2 & $>50 \%$ & $>50 \%$ \\
2 & 70 & 22 & 2 & $>50 \%$ & $>50 \%$ \\
3 & 68 & 21 & 2 & $>50 \%$ & $25 \%$ \\
4 & 52 & 25 & 3 & $>50 \%$ & $25 \%$ \\
5 & 78 & 28 & 2 & $>50 \%$ & $>50 \%$ \\
6 & 56 & 17 & 2 & $>50 \%$ & $0 \%$ \\
7 & 59 & 10 & 2 & $>50 \%$ & $10 \%$ \\
8 & 83 & 20 & 2 & $>50 \%$ & $>50 \%$ \\
9 & 57 & 21 & 3 & $>50 \%$ & $0 \%$ \\
10 & 68 & 15 & 2 & $>50 \%$ & $0 \%$ \\
11 & 65 & 50 & 2 & $>50 \%$ & $0 \%$ \\
\hline
\end{tabular}

NHG, Nottingham histological grade.

All cancers were human epidermal growth factor receptor 2 (HER-2) negative. changes. After the seventh day of incubation, the culture medium was collected and stored at $-70^{\circ} \mathrm{C}$.

\section{Animal studies}

The animal ethics committee at Linköping University approved the mouse studies, and their care and treatment conformed to the regulatory standards. Female athymic nude mice (BALB/c nu/nu) and FVB/N mice (6-8 weeks, Scanbur, Sweden) were housed in individually ventilated cages at Linköping University with a light/dark cycle of 12/12 hours and provided with rodent chow and water ad libitum. The mice were anesthetized with ip injections of ketamine/xylazine, oophorectomized, and then implanted sc with $3-\mathrm{mm}$ pellets containing E2 $(0.18 \mathrm{mg} /$ 60 -day release) (Innovative Research of America), resulting in serum concentrations of 150-250 pM (24).

One week after surgery, the BALB/c nu/nu mice were injected in the dorsal mammary fat pad with MCF-7 cells $\left(5 \times 10^{6}\right.$ cells in $200 \mu \mathrm{lPBS})$. The FVB/N mice were injected in the dorsal mammary fat pad with tumor cells $\left(1 \times 10^{6}\right.$ cells in $200 \mu \mathrm{l}$ PBS $)$ derived from a transgenic mouse strain expressing polyoma middle T (PyMT) antigen under the control of the mouse mammary tumor virus (MMTV) long terminal repeat (25). These mice develop spontaneous adenocarcinomas of the mammary epithelium by $8-10$ weeks of age. The tumors were excised, dissociated in a collagenase/dispase solution (100 ml PBS with $25 \mathrm{mg}$ collagenase and $250 \mathrm{mg}$ dispase) to generate a single-cell suspension, and cultured until confluent. We, and others, have shown that these breast cancers express ER at significant levels during early carcinoma stages, and that the ER levels decrease at later stages $(24,26,27)$. Harvesting tumor tissue in the early stages results in estrogen-dependent cancer growth in the syngeneic recipient mouse $(24,27)$.

\section{Microdialysis of breast cancer in mice}

Tumor-bearing mice were anesthetized with an ip injection of ketamine/xylazine, and a heat lamp was used to maintain body temperature during the procedure. Microdialysis was performed on size-matched tumors without any necrotic areas. Microdialysis catheters (CMA 20, 100-kDa cutoff; CMA Microdialysis $\mathrm{AB})$ were inserted into the tumor tissue and connected to a microdialysis pump (CMA 102; CMA Microdialysis AB) perfused at $0.6 \mu \mathrm{l} / \mathrm{min}$ with Voluven $60 \%$ (Fresenius Kabi AB), as previously described $(28,29)$. After a 60 -minute equilibrium period, the perfusates (microdialysates) were collected and stored at -70 $\mathrm{C}$ for subsequent analysis. The mice were then euthanized, and the tumors were extracted, fixed with formalin, and embedded in paraffin.

\section{Estrogen, progesterone, and adipokine analyses}

Tissue culture medium from normal breast tissue biopsies, plasma samples, and microdialysates were analyzed using human and murine immunoassay kits for adipokines (R\&D Systems) and for estradiol and progesterone (DRG Diagnostics).

\section{Immunohistochemistry}

Formalin-fixed, paraffin-embedded normal breast tissue biopsies and mouse tumors were cut into $4-\mu \mathrm{m}$ sections, deparaffinized, and subjected to high-temperature antigen retrieval prior to incubating with the following primary antibodies: rabbit antihuman leptin (1 $\mu \mathrm{g} / \mathrm{mL}$; GenWay Biotech), goat antihuman LepR (20 $\mu \mathrm{g} / \mathrm{mL}$; AbD Serotec), goat antimouse leptin $(10 \mu \mathrm{g} /$ 
mL; R\&D Systems), goat antimouse LepR (10 $\mu \mathrm{g} / \mathrm{mL}$; R\&D Systems), rabbit antihuman adiponectin $(1 \mu \mathrm{g} / \mathrm{mL}$; Abcam $)$, rabbit antihuman AdipoR1 (5 $\mathrm{g} / \mathrm{mL}$; Bioss), and rabbit antihuman AdipoR2 (5 $\mu \mathrm{g} / \mathrm{mL}$; Bioss). Staining was performed using the secondary antibodies bovine antigoat (Santa Cruz Biotechnology) and goat antirabbit (Envision HRP; DAKO) with the antigoat horseradish peroxidase-3,3'-diaminobenzidine Cell \& Tissue Staining Kit (R\&D Systems). Sections were counterstained using Mayer's hematoxylin (Histolab) and mounted with Pertex mounting medium (Histolab). Negative controls showed no staining. Images of $7-10$ random fields $(\times 400)$ of 3-4 individual tumors in each group were analyzed using an Olympus BX43 microscope. The digital images were collected using an Olympus DP72 camera and analyzed using CellSens Dimension software (Olympus Life Science Europe GmbH).

\section{Statistical analyses}

Groups were compared using paired and unpaired Student [ital]t test, and Pearson's correlation coefficient was used as appropriate; $P<.05$ was considered significant.

\section{Results}

\section{Leptin increased and adiponectin decreased in normal breast tissue during estrogen exposure}

In the healthy premenopausal women, plasma estradiol levels increased from $131 \pm 15 \mathrm{pM}$ in the follicular phase to $406 \pm 52 \mathrm{pM}$ in the luteal phase $(P<.001, \mathrm{n}=11)$, and plasma progesterone levels increased from $1.8 \pm 0.25 \mathrm{nM}$ in the follicular phase to $19.9 \pm 4.7 \mathrm{nM}$ in the luteal phase $(P<.01, \mathrm{n}=11)$. Progesterone levels increased in 10 of the 11 women, suggesting that ovulation had occurred. In the 18 postmenopausal women who had undergone surgical removal of breast cancer, plasma estradiol levels were $73 \pm 12 \mathrm{pM}$ before the start of tamoxifen.

To determine the relationship between plasma estrogen levels and extracellular adipokine levels, we analyzed data from healthy breast tissues of the premenopausal women (in both follicular and luteal phases of a single menstrual cycle) and from breast tissue and sc abdominal fat of the postmenopausal women before the start of tamoxifen. Due to a technical error, no breast tissue sample was collected during the luteal phase from one of the 11 premenopausal women, and no sc abdominal fat tissue was collected from two of the 18 postmenopausal women.

In women with normal breast tissue, plasma estradiol levels positively correlated with local extracellular leptin levels $(\mathrm{r}=0.37, P<.05 ; \mathrm{n}=39)$ and negatively correlated with local extracellular adiponectin levels $(r=-0.34, P<$ $.05 ; \mathrm{n}=39)$ and positively correlated with leptin:adiponectin ratio $(\mathrm{r}=0.38, P<.05 ; \mathrm{n}=39$; Figure $1 \mathrm{~A})$. In contrast, plasma estradiol did not correlate with extracellular adipokine levels in sc abdominal fat (Figure 1B). Similarly, local extracellular estradiol levels in breast tissue positively correlated with extracellular breast leptin levels $(\mathrm{r}=0.42, P<.05)$ and negatively correlated with extracellular adiponectin levels $(\mathrm{r}=-0.42, P<.05)$ and positively correlated with the leptin:adiponectin ratio $(\mathrm{r}=$
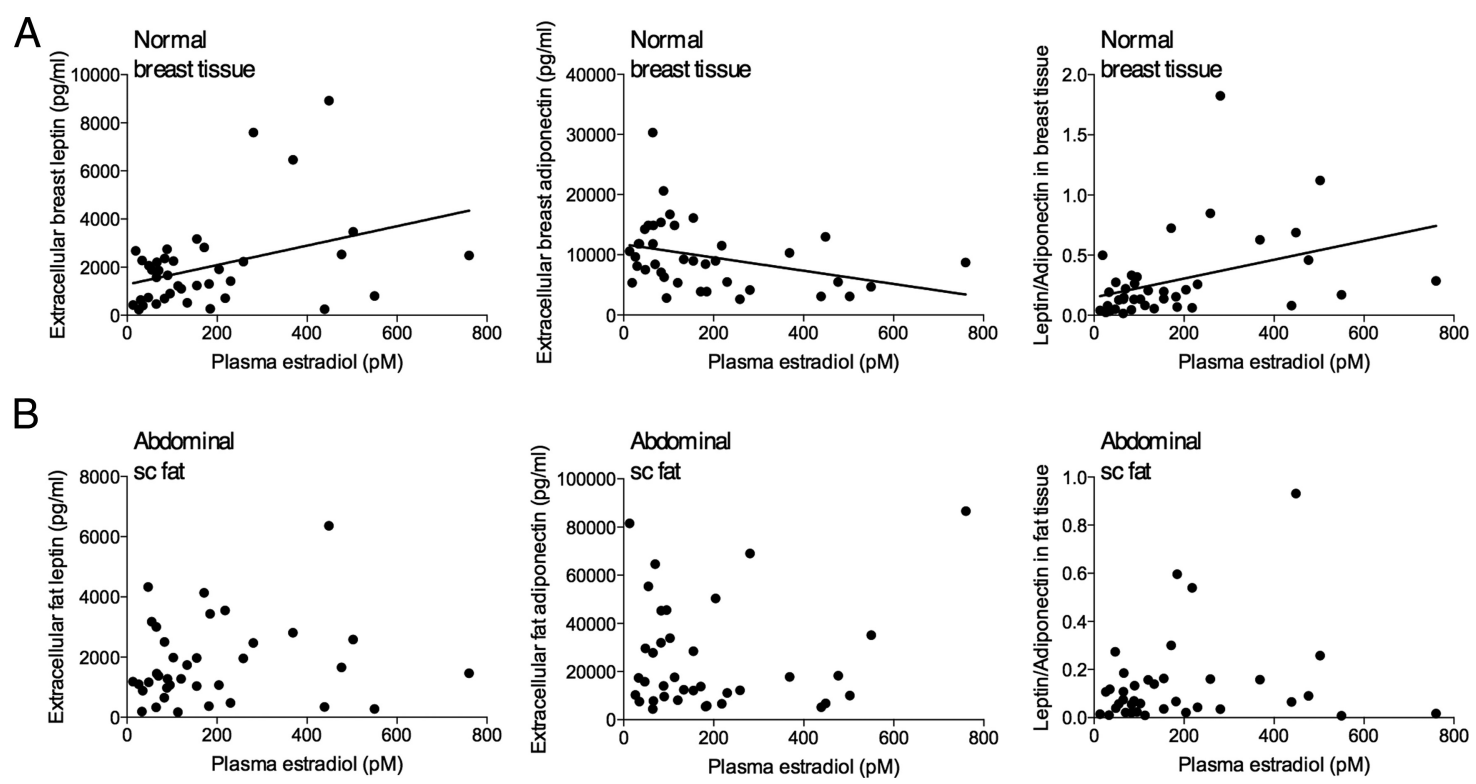

Figure 1. Leptin increased and adiponectin decreased in normal human breast tissue exposed to estrogen. Microdialysis sampling was used to collect extracellular adipokines in normal human breast tissue and sc abdominal fat from both pre- and postmenopausal women. A, Plasma estradiol levels positively correlated with extracellular leptin level $(r=0.37, P<.05, n=39)$ and negatively correlated with the local extracellular adiponectin level $(r=-0.34, P<.05, n=39)$ and positively correlated with the leptin:adiponectin ratio $(r=0.38, P<.05, n=39)$ in normal human breast tissue. B, Plasma estradiol did not correlate with local extracellular adipokine levels in sc abdominal fat or with plasma adipokine levels. 
A
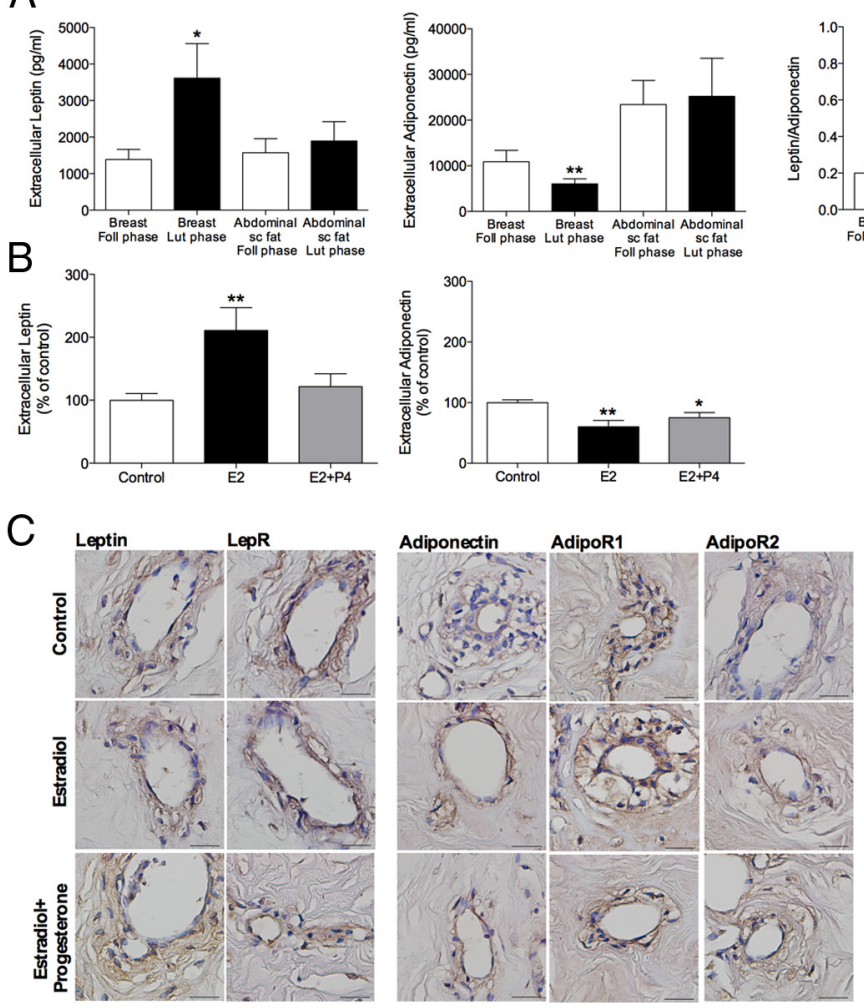

Figure 2. Leptin increased and adiponectin decreased in normal breast tissue exposed to estrogen. A, Healthy premenopausal women $(n=11)$ underwent microdialysis sampling of normal breast tissue and sc abdominal fat tissue in the follicular (Foll) and luteal (Lut) phases of a single menstrual cycle. ${ }^{*}, P<.05 ; * *, P<.01 ; * * *, P<.001$. B, To confirm the in vivo findings, whole normal human breast tissue biopsies were cultured with or without $10^{-9} \mathrm{M}$ estradiol (E2) or a combination of $10^{-9} \mathrm{M}$ estradiol (E2) and $10^{-8} \mathrm{M}$ progesterone (E2 + P4) for 7 days, and adipokine levels in the culture medium were analyzed. **, $P<.01$ compared with controls (each group, $n=9$ ). $C$, Normal breast tissue biopsies were cultured ex vivo with or without $10^{-9} \mathrm{M}$ estradiol (E2) or the combination of $10^{-9} \mathrm{M}$ estradiol and $10^{-8} \mathrm{M}$ progesterone (E2 + P4). Levels of adipokines and their corresponding receptors (leptin receptor [LepR], adiponectin receptor 1 [AdipoR1], and adiponectin receptor 2 [AdipoR2]) were determined by immunohistochemistry analysis. No differences were detected between treatment groups. Representative tissue sections from each treatment group are shown (scale bars, $20 \mu \mathrm{m}$ ).

$0.57, P<.001)$. Plasma estradiol levels did not correlate with plasma adipokine levels.

In the 11 healthy premenopausal women, local extracellular adiponectin levels in the breast tissue were lower in the luteal phase of the menstrual cycle compared with the follicular phase $(P<.01)$, whereas leptin levels and the leptin:adiponectin ratio were higher during the luteal phase $(P<.05$; Figure $2 \mathrm{~A})$.

To confirm these in vivo results, whole normal breast tissue biopsies were cultured ex vivo in the presence or absence of hormones. In estradiol-treated tissues, leptin levels in the culture medium were significantly higher than that of control biopsies $(P<.01, \mathrm{n}=9)$, whereas adiponectin levels were significantly lower $(P<.01, \mathrm{n}=9$; Figure $2 \mathrm{~B})$. The addition of progesterone $(\mathrm{E} 2+\mathrm{P} 4)$ did not change adipokine levels compared with estradiol alone. Immunohistochemical staining of paraffin-embedded normal breast tissue biopsies revealed no changes in the expression of leptin and adiponectin or their corresponding receptors after hormone exposure. Representative sections are shown in Figure 2C.

\section{Tamoxifen significantly decreased leptin and increased adiponectin in normal breast tissue}

To determine whether adipokines levels could be modulated by antiestrogen therapy, we performed microdialysis in postmenopausal women who received tamoxifen as an adjuvant therapy. After 6 weeks of tamoxifen treatment, leptin levels were significantly decreased in normal breast tissue $(P<.01, \mathrm{n}=18)$, and adiponectin levels were significantly increased $(P<.05, \mathrm{n}=18$; Figure 3A). In addition, the leptin:adiponectin ratio was significantly decreased after tamoxifen treatment $(P<.01, \mathrm{n}=18)$. However, leptin and adiponectin levels in plasma and sc abdominal fat did not change significantly during tamoxifen treatment.

These results were confirmed in ex vivo culture of normal breast tissue biopsies, which showed decreased secretion of leptin $(P<$ $.0001, \mathrm{n}=9$ ) and increased secretion of adiponectin after tamoxifen exposure $(P<.05, \mathrm{n}=12$; Figure $3 \mathrm{~B})$. However, immunohistochemical staining of the paraffin-embedded normal breast tissue biopsies revealed no significant changes in the expression of leptin and adiponectin or their corresponding receptors after tamoxifen exposure (Figure 3C).

\section{Increased leptin and decreased adiponectin in human breast cancer in vivo}

These results in normal breast tissue encouraged us to investigate whether human breast cancer exhibited extracellular adipokines, and whether their levels were altered compared with normal adjacent breast tissue. Therefore, we performed microdialysis in breast cancer tissues before surgical removal. We found that leptin levels were significantly higher in breast cancer tumors compared with normal adjacent breast tissue $(P<.01, \mathrm{n}=11)$, whereas adiponectin levels were significantly lower $(P<.05$; Figure $4 \mathrm{~A})$. Accordingly, the leptin:adiponectin ratio was higher in tumors than in the adjacent tissue $(P<.01)$. 
A

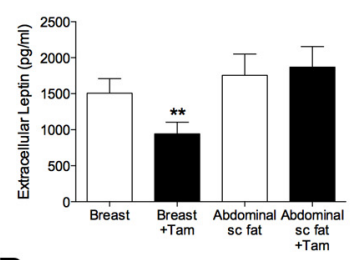

$\mathrm{B}$

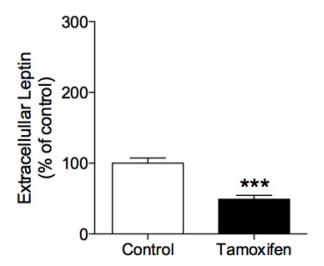

C

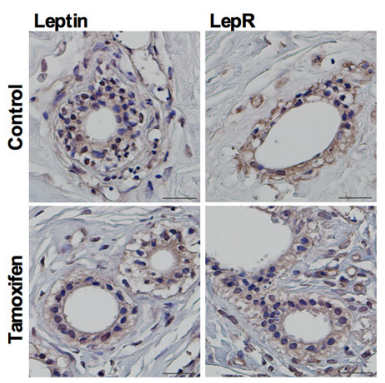

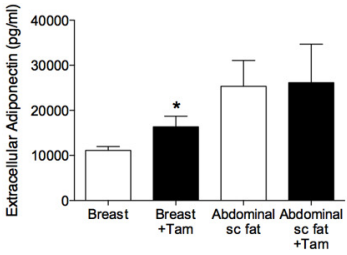
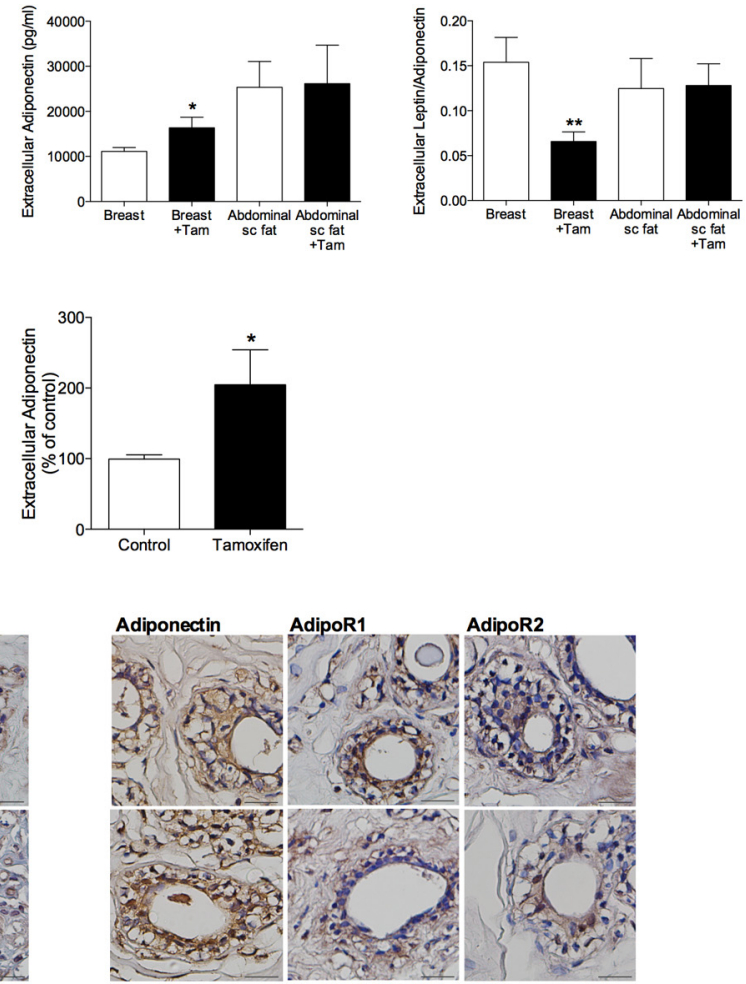

Figure 3. Tamoxifen significantly decreased leptin and increased adiponectin in normal human breast tissue. A, Postmenopausal women underwent microdialysis sampling of breast tissue $(n=$ 18) and sc abdominal fat $(n=16)$ before tamoxifen treatment and 6 weeks after treatment. *, $P<.05 ;{ }^{*}, P<.01$. B, To confirm the in vivo findings, whole normal human breast tissue biopsies were cultured with or without $10^{-6} \mathrm{M}$ tamoxifen (Tam) for 7 days, and adipokine levels in the culture medium were determined. ${ }^{*}, P<.05(n=9) ; * * * *, P<.0001(n=12)$ compared with controls. C, Normal breast tissue biopsies were cultured ex vivo with or without $10^{-6} \mathrm{M}$ tamoxifen (Tam). Levels of adipokines and their corresponding receptors (leptin receptor [LepR], adiponectin receptor 1 [AdipoR1], and adiponectin receptor 2 [AdipoR2]) were determined by immunohistochemistry analysis. No differences were detected between treatment groups. Representative tissue sections from each treatment group are shown (scale bars, $20 \mu \mathrm{m}$ ).

more intense in tumors grown in the presence of estradiol (Figure 4C).

\section{Discussion}

In this study, we used microdialysis for in situ sampling of extracellular adipokines in normal human breast tissue and breast cancer tumors. In normal human breast tissue but not sc abdominal fat, estradiol positively correlated with leptin levels and negatively correlated with adiponectin levels. A hormone-dependent release of leptin and adiponectin was also observed in ex vivo cultures of normal human breast tissue biopsies. As we hypothesized, tamoxifen decreased leptin levels and increased adiponectin levels in normal breast tissue in vivo and ex vivo. In patients with breast cancer, leptin levels were significantly increased and adiponectin levels significantly decreased in the tumors compared with adjacent normal breast tissue. In a murine model of breast cancer, estradiol increased extracellular leptin levels and expression of the leptin receptor.

According to autopsy reports, $15-30 \%$ of all women have breast cancer in situ, but only $1 \%$ of women

\section{Estradiol treatment increased leptin levels and leptin:adiponectin ratio in a murine breast cancer model}

To further elucidate the effect of hormone exposure on adipokine secretion in breast cancer, we used two different murine breast cancer models. In athymic BALB/c nu/nu mice bearing MCF-7 tumors, local extracellular levels of leptin and adiponectin were not detectable by microdialysis sampling or immunohistochemical staining of the paraffin-embedded tumors. However, in FVB/N mice bearing MMTV-PyMT tumors, we found that cancers grown in presence of estradiol exhibited higher leptin levels $(P<$ $.05)$ and leptin:adiponectin ratios $(P<.05)$ compared with cancers in estrogen-depleted mice ( $n=7$; Figure $4 B)$. Adiponectin levels seemed to be decreased in the presence of estradiol, but this difference was not significant $(P=$ $.08 ; \mathrm{n}=7$; Figure 4B). Expression of the adipokines and AdipoR1 and AdipoR2 did not differ significantly differ between treatment groups; however, LepR staining was in the same age group are diagnosed with breast cancer (30). Conversion of these in situ breast cancers into invasive, clinically relevant breast cancer may be mediated by changes in the microenvironment. Although breast tissue is most active during pregnancy and lactation, normal breast tissue also undergoes changes during periods of lower hormone exposure, such as the menstrual cycle, and in women receiving hormone replacement therapy $(2,31$, 32). Mammary adipose tissue is an important source of bioactive factors involved in paracrine signaling. Among them, leptin has been shown to stimulate cancer cell growth, inhibit apoptosis, induce angiogenesis, and promote the migration and invasion of tumor cells (33). Results of previous in vitro studies suggest that estrogen exposure increases leptin production and LepR expression in human sc fat and rat brain tissue $(34,35)$. However, no previous studies have investigated local extracellular leptin levels in human breast tissue. Previous studies on adi- 

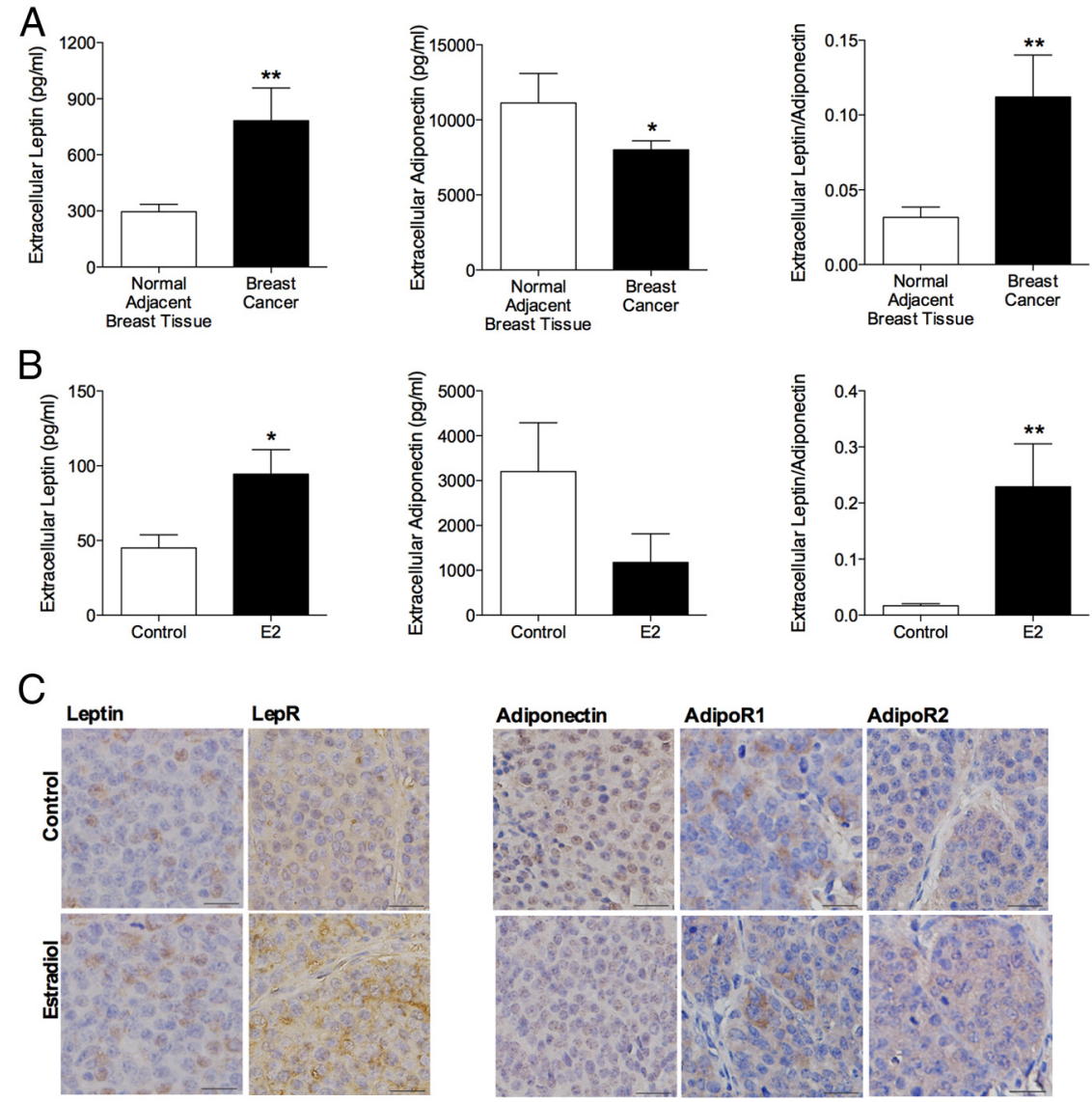

Figure 4. Increased extracellular leptin and decreased adiponectin in human breast cancer in vivo. A) Eleven postmenopausal patients with breast cancer underwent microdialysis sampling of the tumor and normal adjacent breast tissue before surgery. ${ }^{*}, P<.05 ;{ }^{*} *, P<.01$. B) FVB/N mice were oophorectomized and treated with or without estradiol (physiologic level), and MMTV-PyMT mammary cancer cells were injected into the dorsal mammary fat pad. At similar tumor sizes, both groups of mice underwent microdialysis sampling of adipokines in the tumor. $*, P<.05 ; * *, P<.01$ (each group, $n=7$ ). C) FVB/N mice were treated as described in Figure 4B. Levels of adipokines and their corresponding receptors (leptin receptor [LepR], adiponectin receptor 1 [AdipoR1], and adiponectin receptor 2 [AdipoR2]) in the MMTV-PyMT tumors were determined by immunohistochemistry analysis. Increased LepR staining was observed in estrogen-exposed tumors. Representative tissue sections from each treatment group are shown (scale bars, $20 \mu \mathrm{m}$ ).

ponectin protein expression evaluated either circulating levels or expression in paraffin-embedded tumor samples. However, leptin and adiponectin exert their effects in the extracellular microenvironment, and the lack of simple techniques and appropriate models has made quantification of tissue-specific levels of these proteins difficult to perform. In this study results obtained by microdialysis sampling, which enables the continuous collection of molecules in the extracellular space $(21,36-38)$, suggest that estrogen regulates the secretion of leptin in normal human breast tissue.

In breast cancer, studies have reported that crosstalk between estrogen and leptin is involved in the regulation of aromatase activity and ER $\alpha$ expression, which supports the importance of these factors in estrogen-dependent breast cancer growth $(8-10)$. On the other hand, adiponectin seems to reduce aromatase activity and ER
mRNA levels, thereby inhibiting the effects of estrogen on the proliferation of breast cancer cells $(10,39$, 40). These results suggest that a microenvironment with high leptin levels and low adiponectin levels increases breast cancer risk, which is supported by studies evaluating blood levels of these adipokines (12, 15, 19). Our data suggest that leptin and adiponectin levels in normal human breast tissue may be under hormonal control during the menstrual cycle and in postmenopausal women. In addition, the relevance of extracellular leptin and adiponectin as targets in human breast cancer was confirmed by our data, with leptin levels almost three times higher and adiponectin significantly lower in tumors compared with adjacent normal breast tissue in patients with breast cancer. Because of the limited number of patients with breast cancer, we investigated a possible estrogen-dependent release of adipokines in murine experimental models, and found that estrogen exposure increased extracellular leptin secretion and the leptin:adiponectin ratio in vivo.

Cytokines act on their target cells by binding to transmembrane receptors. Previous studies have reported increased expression of both leptin and LepR in human breast carcinoma compared with normal mammary tissue $(21,41)$. In our study, receptor expression in normal human breast tissue biopsies was not altered by hormone exposure; however, estrogen-exposed MMTVPyMT tumors in mice exhibited increased LepR expression, suggesting that hormone exposure may increase LepR expression in breast cancer tumors but not in normal breast tissue.

In summary, our results suggest that leptin and adiponectin are under hormonal control in normal human breast tissue and that these proteins are druggable targets, responding to antiestrogen therapy in postmenopausal women. Our in vivo data from patients with breast cancer confirmed the relevance of these extracellular proteins. We conclude that leptin and adiponectin may be molecular targets for future therapeutic and prevention strategies in estrogen-dependent breast cancer. 


\section{Acknowledgments}

Address all correspondence and requests for reprints to: Charlotta Dabrosin, MD PhD, Professor of Oncology, Linköping University, Division of Oncology, SE-581 85 Linköping, Sweden. E-mail: charlotta.dabrosin@liu.se.

This work was supported by grants from the Swedish Cancer Society (2012/454 to C.D.), Swedish Research Council (20103458 to C.D.), and Research Funds of Linköping University Hospital (C.D.).

Disclosure Summary: The authors have nothing to disclose.

\section{References}

1. Beral V. Breast cancer and hormone-replacement therapy in the Million Women Study. Lancet. 2003;362:419-427.

2. Hulka BS, Stark AT. Breast cancer: cause and prevention. Lancet. 1995;346:883-887.

3. Russo J, Russo IH. The role of estrogen in the initiation of breast cancer. J Steroid Biochem Mol Biol. 2006;102:89-96.

4. Santen R, Cavalieri E, Rogan E, et al. Estrogen mediation of breast tumor formation involves estrogen receptor-dependent, as well as independent, genotoxic effects. Ann N Y Acad Sci. 2009;1155:132-140.

5. Cuzick J, Powles T, Veronesi U, et al. Overview of the main outcomes in breast-cancer prevention trials. Lancet. 2003;361:296-300.

6. Davies C, Godwin J, Gray R, et al. Relevance of breast cancer hormone receptors and other factors to the efficacy of adjuvant tamoxifen: patient-level meta-analysis of randomised trials. Lancet. 2011; 378:771-784.

7. Kershaw EE, Flier JS. Adipose tissue as an endocrine organ. J Clin Endocrinol Metab. 2004;89:2548-2556.

8. Catalano S, Marsico S, Giordano C, et al. Leptin enhances, via AP-1, expression of aromatase in the MCF-7 cell line. J Biol Chem. 2003; 278:28668-28676.

9. Yu W, Gu JC, Liu JZ, et al. Regulation of estrogen receptors alpha and beta in human breast carcinoma by exogenous leptin in nude mouse xenograft model. Chin Med J (Engl). 2010;123:337-343.

10. Jardé T, Caldefie-Chézet F, Goncalves-Mendes N, et al. Involvement of adiponectin and leptin in breast cancer: clinical and in vitro studies. Endocr Relat Cancer. 2009;16:1197-1210.

11. Vona-Davis L, Rose DP. Adipokines as endocrine, paracrine, and autocrine factors in breast cancer risk and progression. Endocr Relat Cancer. 2007;14:189-206.

12. Mantzoros C, Petridou E, Dessypris N, et al. Adiponectin and breast cancer risk. J Clin Endocrinol Metab. 2004;89:1102-1107.

13. Yamauchi T, Kamon J, Ito Y, et al. Cloning of adiponectin receptors that mediate antidiabetic metabolic effects. Nature. 2003;423:762-769.

14. Miyoshi Y, Funahashi T, Kihara S, et al. Association of serum adiponectin levels with breast cancer risk. Clin Cancer Res. 2003;9: 5699-5704.

15. Tworoger SS, Eliassen AH, Kelesidis T, et al. Plasma adiponectin concentrations and risk of incident breast cancer. J Clin Endocrinol Metab. 2007;92:1510-1516.

16. Nkhata KJ, Ray A, Schuster TF, Grossmann ME, Cleary MP. Effects of adiponectin and leptin co-treatment on human breast cancer cell growth. Oncol Rep. 2009;21:1611-1619.

17. Taliaferro-Smith L, Nagalingam A, Knight BB, et al. Integral role of PTP1B in adiponectin-mediated inhibition of oncogenic actions of leptin in breast carcinogenesis. Neoplasia. 2013;15:23-38.

18. Cleary MP, Ray A, Rogozina OP, Dogan S, Grossmann ME. Targeting the adiponectin:leptin ratio for postmenopausal breast cancer prevention. Front Biosci (Schol Ed). 2009;1:329-357.

19. Chen DC, Chung YF, Yeh YT, et al. Serum adiponectin and leptin levels in Taiwanese breast cancer patients. Cancer Lett. 2006;237: 109-114.
20. Dabrosin C, Ollinger K, Ungerstedt U, Hammar M. Variability of glutathione levels in normal breast tissue and subcutaneous fat during the menstrual cycle: an in vivo study with microdialysis technique. J Clin Endocrinol Metab. 1997;82:1382-1384.

21. Dabrosin C, Hallstrom A, Ungerstedt U, Hammar M. Microdialysis of human breast tissue during the menstrual cycle. Clin Sci (Lond). 1997;92:493-496.

22. Dabrosin C. Variability of Vascular Endothelial Growth Factor in Normal Human Breast Tissue in Vivo during the Menstrual Cycle. J Clin Endocrinol Metab. 2003;88:2695-2698.

23. Dabrosin C. Technical aspects of microdialysis of human breast. Scand J Clin Lab Invest. 2001;61:269-272.

24. Dabrosin C, Palmer K, Muller WJ, Gauldie J. Estradiol promotes growth and angiogenesis in polyoma middle $\mathrm{T}$ transgenic mouse mammary tumor explants. Breast Cancer Res Treat. 2003;78:1-6.

25. Guy CT, Cardiff RD, Muller WJ. Induction of mammary tumors by expression of polyomavirus middle T oncogene: a transgenic mouse model for metastatic disease. Mol Cell Biol. 1992;12:954-961.

26. Lin EY, Jones JG, Li P, et al. Progression to malignancy in the polyoma middle $\mathrm{T}$ oncoprotein mouse breast cancer model provides a reliable model for human diseases. Am J Pathol. 2003;163:2113-2126.

27. Dabrosin C, Margetts PJ, Gauldie J. Estradiol increases extracellular levels of vascular endothelial growth factor in vivo in murine mammary cancer. Int J Cancer. 2003;107:535-540.

28. Garvin S, Dabrosin C. Tamoxifen inhibits secretion of vascular endothelial growth factor in breast cancer in vivo. Cancer Res. 2003; 63:8742-8748.

29. Lindahl G, Saarinen N, Abrahamsson A, Dabrosin C. Tamoxifen, flaxseed, and the lignan enterolactone increase stroma- and cancer cell-derived IL-1Ra and decrease tumor angiogenesis in estrogendependent breast cancer. Cancer Res. 2011;71:51-60.

30. Welch HG, Black WC. Using autopsy series to estimate the disease "reservoir" for ductal carcinoma in situ of the breast: how much more breast cancer can we find? Ann Intern Med. 1997;127:1023-1028.

31. Key TJ. Endogenous oestrogens and breast cancer risk in premenopausal and postmenopausal women. Steroids. 2011;76:812-815.

32. Narod SA. Hormone replacement therapy and the risk of breast cancer. Nat Rev Clin Oncol. 2011;8:669-676.

33. Andò S, Catalano $S$. The multifactorial role of leptin in driving the breast cancer microenvironment. Nat Rev Endocrinol. 2012;8:263275.

34. Machinal-Quélin F, Dieudonné MN, Pecquery R, Leneveu MC, Giudicelli Y. Direct in vitro effects of androgens and estrogens on ob gene expression and leptin secretion in human adipose tissue. Endocrine. 2002;18:179-184.

35. Bennett PA, Lindell K, Karlsson C, Robinson IC, Carlsson LM, Carlsson B. Differential expression and regulation of leptin receptor isoforms in the rat brain: effects of fasting and oestrogen. Neuroendocrinology. 1998;67:29-36.

36. Dabrosin C. Microdialysis - an in vivo technique for studies of growth factors in breast cancer. Front Biosci. 2005;10:1329-1335.

37. Dabrosin C. Increase of free insulin-like growth factor-1 in normal human breast in vivo late in the menstrual cycle. Breast Cancer Res Treat. 2003;80:193-198.

38. Dabrosin C. Increased extracellular local levels of estradiol in normal breast in vivo during the luteal phase of the menstrual cycle. $J$ Endocrinol. 2005;187:103-108.

39. Dieudonne MN, Bussiere M, Dos Santos E, Leneveu MC, Giudicelli Y, Pecquery R. Adiponectin mediates antiproliferative and apoptotic responses in human MCF7 breast cancer cells. Biochem Biophys Res Commun. 2006;345:271-279.

40. Treeck O, Lattrich C, Juhasz-Boess I, Buchholz S, Pfeiler G, Ortmann O. Adiponectin differentially affects gene expression in human mammary epithelial and breast cancer cells. Br J Cancer. 2008; 99:1246-1250.

41. Ishikawa M, Kitayama J, Nagawa H. Enhanced expression of leptin and leptin receptor (OB-R) in human breast cancer. Clin Cancer Res. 2004;10:4325-4331. 